\title{
Cosas de mujeres: familias monoparentales dominicanas en Barcelona y Nueva York
}

\author{
Rosalina Alcalde \\ Universitat Autònoma de Barcelona \\ rosalina.alcalde@uab.cat
}

Resumen: Numerosos estudios a escala internacional y española avalan en la actualidad el riesgo de pobreza que presentan los hogares monoparentales encabezados por mujeres en las sociedades contemporáneas desarrolladas. Este artículo recoge algunos de los principales resultados de sendas investigaciones llevadas a cabo en las ciudades de Barcelona y Nueva York sobre la incidencia de estas formas de hogar entre las mujeres inmigrantes, focalizando el análisis en las mujeres dominicanas.

Palabras clave: familia monoparental, inmigración, pobreza, inmigración dominicana.

Abstract: Several international and Spanish studies have shown that one-parent families are at considerable risk of poverty in contemporary and developed societies, particularly when the mother is the head, which is usually the case. This paper provides the main results of some research carried out in Barcelona and New York about one-parent families and immigrant women, with particular emphasis on Dominican women.

Keywords: one-parent families, immigration, poverty, Dominican immigration 


\section{Introducción}

Numerosos estudios, a escala tanto internacional como española y catalana, han puesto de relieve que uno de los principales riesgos de pobreza $-y$ de pobreza infantil - en los países desarrollados es, en la actualidad, la monoparentalidad familiar (Flaquer, Almeda y Navarro, 2007; Ayala, Martínez y Sastre, 2006; Garfinkel y McLanahan, 1994). De hecho, el trabajo de Flaquer, Almeda y Navarro revela que, precisamente en España, el aumento de este riesgo ha sido muy superior al de otros países desarrollados. Con todo, en el artículo que aquí se presenta se demuestra que la relación entre pobreza y monoparentalidad no se da siempre, ni con la misma intensidad ni en el mismo sentido (monoparentalidad igual a riesgo de pobreza) en función de los diversos grupos sociales y étnicos a los que nos refiramos. El caso de los países latinoamericanos es un claro ejemplo de cómo la pobreza constituye, con frecuencia, una causa previa que explica el aumento de este tipo de hogares (Oliveira y Ariza, 2007). Pero también en países como los EE.UU. la monoparentalidad afecta mucho más a aquellos grupos que históricamente han ocupado las posiciones sociales más subordinadas: el de las mujeres, $y$ en particular las afroamericanas y las inmigrantes de origen latino. Se demostrará cómo en España este tipo de hogar también se da en mayor medida entre el conjunto de mujeres inmigrantes que entre las mujeres españolas. Se constatará que existe una evidente relación entre pobreza, monoparentalidad y proyecto migratorio.

Los resultados que se presentarán han sido extraídos de la investigación La monomarentalidad en la inmigración: el riesgo de pobreza entre madres e hijos de origen extranjero (2010) — proyecto financiado por el Institut Català de la Dona (dependiente de la Generalitat de Cataluña) - y del trabajo de campo realizado en Nueva York con el apoyo del Dominican Studies Institute del City College of New York (2010) - financiado a través de la Agencia de Gestión y Ayudas Universitarias en la convocatoria de becas para la realización de estancias de investigación en centros extranjeros-.

En este artículo se planteará, en primer lugar, la pertinencia del estudio de la monoparentalidad entre las mujeres migrantes y dominicanas en los EE.UU. y en España, para en segunda instancia dilucidar la relación entre monoparentalidad, pobreza e inmigración en dos contextos subnacionales como son Nueva York y Barcelona. Los temas que se abordarán serán estos:

a) La relación entre pobreza y monoparentalidad. Su incidencia entre las mujeres inmigrantes. 
b) Las vías de entrada a la monoparentalidad entre las mujeres dominicanas inmigrantes y las condiciones de vida de estas familias en Barcelona y Nueva York.

c) La monoparentalidad y su relación con el proyecto migratorio (emancipación, supervivencia del grupo doméstico, otros aspectos).

d) Las condiciones de vida de los miembros de hogares monoparentales (hijos, madres) encabezados por mujeres migrantes latinoamericanas en Nueva York y en Barcelona.

\section{Metodología}

La metodología utilizada en esta investigación combina la explotación de datos estadísticos secundarios con una metodología cualitativa basada en las entrevistas.

Por lo que se refiere al trabajo de campo cualitativo, en Barcelona se eligieron dieciocho familias de diferentes nacionalidades latinoamericanas (4 mujeres de nacionalidad ecuatoriana; 4 de nacionalidad dominicana; 3 de nacionalidad peruana, 4 de nacionalidad colombiana, y 3 de nacionalidad boliviana) y tres familias de control de nacionalidad española. La configuración de las regiones y nacionalidades se realizó en función de la relevancia metodológica del origen nacional, considerando tanto la consolidación del flujo migratorio hacia España y Barcelona (Cataluña) como el grado de feminización del flujo y la incidencia de la monoparentalidad entre estas nacionalidades.

Las variables de homogeneidad utilizadas para la selección de las familias hacia las que se orientó el trabajo de campo cualitativo fueron: núcleos familiares monoparentales encabezados por mujeres extranjeras inmigrantes de nacionalidades latinoamericanas, residentes en la provincia de Barcelona, a cargo de hijos menores de 18 años, con experiencia de escolarización en España y que estuvieran realizando estudios secundarios. Por otro lado, las variables de heterogeneidad contempladas fueron la nacionalidad, la edad, el país donde se produjo la entrada en la monoparentalidad (origen-destino), el nivel sociocultural de la madre y la vía de entrada a la monoparentalidad.

Para el trabajo de campo en la ciudad de Nueva York se optó por un trabajo intensivo con mujeres dominicanas, dada la alta incidencia de esta forma de hogar en este colectivo - como sucede también con las mujeres dominicanas residentes en España-. Se realizaron seis entrevistas a mujeres dominicanas cabezas de familias monoparentales con hijos menores de edad. Si bien la mayor parte de ellas responden a perfiles de segunda generación - mujeres reagrupadas por sus 
padres-, lo que aporta elementos difícilmente comparativos con las mujeres entrevistadas en España, permiten visibilizar un perfil aún muy poco conocido en nuestro país, enriqueciendo de este modo el análisis.

\section{Tú a Barcelona, yo a Nueva York‡ orígenes de la in- migración dominicana en los EE.UU. y en España}

La inmigración dominicana en España no ha tenido hasta el momento la misma intensidad que en los Estados Unidos de América. Podría parecernos que se trata de un flujo migratorio reciente, pero lo cierto es que los ciudadanos dominicanos llevan migrando intensamente fuera de su país desde hace más de cuarenta años; España comenzó a configurarse como destino de su migración hacia la década de 1960.

Los EE.UU. han venido siendo el principal país receptor de la inmigración dominicana. Datos oficiales recientes publicados por la oficina del censo americano indicaban en sus estimaciones que, para el año 2008, esta población era de 1.249.471 (el 0,4\% de la población de los EE.UU.). De este modo, al inicio de la actual década la población dominicana constituía el cuarto colectivo hispano/ latino más populoso del país norteamericano, después del mexicano, el puertorriqueño y el cubano.

En EE.UU,, los dominicanos han escogido con preferencia el Estado de Nueva York y la ciudad de Nueva York como lugares de asentamiento a lo largo de estas últimas décadas. En 1990, el 70\% de la inmigración dominicana estaba instalada en este estado, mientras que en el año 2000 las estimaciones eran del $59,3 \%$. - un 22,11\% en la ciudad más populosa del mismo, Nueva York-; la segunda posición la ocupaba el estado vecino de Nueva Jersey, con un 13,1\% (Hernández, 2003).

En relación a Europa, antes de la década de 1980 ya se había registrado una tímida inmigración de este colectivo en España. Autores como Romero (2003) lo calificaron como un goteo migratorio que se mantuvo durante el primer lustro de la década de 1960, con una ligera tendencia alcista sobre todo a partir del asesinato del presidente dominicano Rafael Leónidas Trujillo ${ }^{1}$ en 1961. En esta línea, y según Sorensen (1996), la migración dominicana hacia España durante esta época había sido motivada primordialmente por la educación, la aventura y el trabajo en el cuerpo diplomático/consular, o bien en empresas y firmas españolas o multinacionales localizadas en nuestro país (Gallardo Rivas, 1995; citado por Sorensen, 1996).

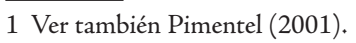


Las causas que explican por qué este flujo escogió España como país de destino a partir de mediados de los años ochenta y durante la década siguiente las hayamos tanto en los factores de expulsión que se habían mantenido constantes en las últimas décadas en la Republica Dominicana — deterioro de las condiciones de vida, malestar e insatisfacción de una gran parte de la población dominicana debido a la crisis del modelo agroexportador, el empuje de una demografía en crecimiento y el incremento extraordinario de la población en edad de trabajar, la deficiente gestión pública de los sucesivos gobiernos (Romero, 2003; Pimentel, 2001) - , como en los factores de atracción de la economía española -crecimiento económico y demanda de empleadas en el servicio domestico y el sector servicios-. Resulta igualmente relevante considerar como factores las relaciones económicas establecidas entre la Republica Dominicana y España, así como la afinidad cultural y los lazos históricos presentes entre ambos países. Del mismo modo, debemos apreciar la existencia de un «efecto rebote» como consecuencia del aumento paulatino de la dificultad a la hora de entrar en los EE.UU. y poder residir de forma irregular, debido al endurecimiento de la ley de extranjería norteamericana -Immigration Reform and Control Act (IRCA) de 1986; y quizás en menor medida de la Immigration Act de 1990 (Romero, 2003)—. En conclusión, en el año 2010 residían en nuestro país 90.195 personas de nacionalidad dominicana ${ }^{2}$, lo que representaba el 1,9\% de la población extranjera en nuestro país (Padrón Municipal de Habitantes, INE).

Madrid y Barcelona, ciudades que, al igual que Nueva York, ofrecen una mayor diversidad de oportunidades laborales, se han convertido en los dos grandes focos de atracción de la inmigración dominicana en España. La buena conexión entre las dos principales capitales españolas y la República Dominicana, gracias al progresivo abaratamiento de los costes de los abundantes medios de transporte disponibles, aproxima a estas dos metrópolis a esta zona del Caribe, lo que permite que el $36 \%$ de las personas de nacionalidad dominicana residan en la Comunidad de Madrid - primordialmente en la ciudad de Madrid - y el $24,1 \%$ en Cataluña, fundamentalmente en la provincia de Barcelona (19\%).

2 Si consideramos la categoría "país de nacimiento» en lugar de "país de nacionalidad», aparecen contabilizadas 136.803 personas nacidas en la República Dominicana. 


\section{Mujeres y niños en el flujo de inmigración domini- cana hacia los EE.UU. y España}

Un hecho notable, tanto en el flujo migratorio de dominicanos a los EE.UU. como hacia España, es su enorme feminización, lo que responde a una de las principales características de las migraciones internacionales contemporáneas. Las mujeres, si bien siempre han formado parte de los flujos de inmigración internacional, durante años se han mantenido invisibles tras los proyectos migratorios de padres y esposos. Es ahora cuando ellas se entrevén con fuerza, gracias a que se han convertido en las cabezas del proyecto migratorio y, también en numerosos casos, de sus respectivos hogares. Tanto las causas de esa «jefatura» de hogar como las de la emigración son diversas y están relacionadas con aspectos emancipadores y con la pobreza.

En el caso concreto de la migración de mujeres de la República Dominicana, éstas han mantenido una elevada presencia desde el inicio de la emigración intensiva hacia los EE.UU. La entrada previa de capitales extranjeros al país, así como la reestructuración del modelo agrícola orientado a la exportación, provocaron también entre las mujeres un elevado número de desempleadas, que necesariamente se sumaron al flujo de emigración que se generó en el país - FernandezKelly, 1983; Sassen, 1981, 1989; Arraigada, 1992; Brydon y Chant, 1993; Safa, 1995 (citados por Weyland, 1998) — . Durante los años setenta, las mujeres dominicanas se convirtieron en uno de los principales grupos que surtían de mano de obra a los nuevos talleres textiles neoyorquinos que establecieron una relación de libre comercio con Santo Domingo a través de la instalación de zonas francas (Weyland, 1998; Gregorio y Ramírez, 2000; Georges, 1992; Ariza, 2004). Por ese motivo, también ellas se vieron segmentadas en este ámbito laboral, con salarios bajos y precarias condiciones laborales.

La marginalización de las mujeres dominicanas en el mercado laboral de la República Dominicana se encuentra entre las causas para emigrar fuera del país, primordialmente hacia los EE.UU., destino que se materializa como el deseo de un nuevo estilo de vida y de nuevas oportunidades para ellas y sus familias. Inicialmente, la migración de las mujeres dominicanas hacia los EE.UU. se integraba dentro de proyectos migratorios encabezados por los esposos o padres. Este hecho ha ido cambiando con el paso de las décadas. Las mujeres han ido tomando de manera paulatina el timón de estos proyectos, fundamentalmente en el flujo migratorio hacia España (Gregorio y Ramírez, 2000). La demanda de mano de obra femenina en el sector del trabajo doméstico, como consecuencia tanto de la incorporación de las mujeres españolas al trabajo productivo como de 
la extensión de los estilos de vida propios de las clases medias, son los dos factores que explican este fenómeno (Hernanz, 1997). El reclamo de trabajadoras dispensadoras de cuidados a personas dependientes - esencialmente la primera infancia y los ancianos - se explica también por el escaso protagonismo que en este ámbito desarrolla el estado de bienestar español. Pero existen también otros motivos para la emigración: la búsqueda de una vida emancipada y de una existencia autónoma, o la superación de unas relaciones patriarcales.

Lo cierto es que en el caso particular del flujo de migración dominicano, la presencia de las mujeres es indudablemente considerable. De este modo, en 2008, en el Estado de Nueva York, el 54\% de las personas dominicanas que allí residían eran mujeres; esta proporción subía al 57\% en el caso de España, en el año 2010, aunque considerando únicamente la población mayor de 18 años de edad - es decir, excluyendo a los menores, mucho más representados en EE.UU.-, los valores son similares a España. Con todo, resulta interesante comprobar cómo la población dominicana residente en EE.UU. está ciertamente más feminizada que la población total, que las personas blancas y que otros grupos latinoamericanos de gran presencia en este país.

Tabla 1. Población por sexo y grupo racial. EE.UU., 2008.

\begin{tabular}{|l|c|c|c|c|c|c|}
\hline & $\begin{array}{c}\text { Población } \\
\text { total }\end{array}$ & $\begin{array}{c}\text { Población } \\
\text { dominicana }\end{array}$ & $\begin{array}{c}\text { Población } \\
\text { blanca }\end{array}$ & $\begin{array}{c}\text { Población } \\
\text { mexicana }\end{array}$ & $\begin{array}{c}\text { Población } \\
\text { puertorriqueña }\end{array}$ & $\begin{array}{c}\text { Población } \\
\text { cubana }\end{array}$ \\
\hline Hombres & $49.30 \%$ & $46.20 \%$ & $49.30 \%$ & $52.60 \%$ & $49.30 \%$ & $50.20 \%$ \\
\hline Mujeres & $50.70 \%$ & $53.80 \%$ & $50.70 \%$ & $47.40 \%$ & $50.70 \%$ & $49.80 \%$ \\
\hline
\end{tabular}

Fuente: Selected Population Profiles, American Community Survey.

En el caso español, también se detecta una feminización del flujo dominicano por encima de otras nacionalidades americanas de alta representación en España, como son los colectivos colombiano y peruano.

Entre estos flujos feminizados de emigración encontramos, al mismo tiempo, una alta presencia de menores. La población dominicana menor de 18 años de edad alcanza en los EE.UU. una mayor representación en comparación al total de población del país, como así también sucede con respecto únicamente a la población blanca, aunque, en todo caso, en menor medida que entre la población de origen mexicano y puertorriqueño. 
Tabla 2. Población por grupo de edad y grupo racial. EE.UU., 2008.

\begin{tabular}{|l|c|c|c|c|c|c|}
\hline & $\begin{array}{c}\text { Población } \\
\text { total }\end{array}$ & $\begin{array}{c}\text { Población } \\
\text { dominicana }\end{array}$ & $\begin{array}{c}\text { Población } \\
\text { blanca }\end{array}$ & $\begin{array}{c}\text { Población } \\
\text { mexicana }\end{array}$ & $\begin{array}{c}\text { Población } \\
\text { puertorriqueña }\end{array}$ & $\begin{array}{c}\text { Población } \\
\text { cubana }\end{array}$ \\
\hline $\begin{array}{l}\text { Menos de } 5 \\
\text { años }\end{array}$ & $6.9 \%$ & $9.0 \%$ & $6.2 \%$ & $12.2 \%$ & $10.0 \%$ & $6.2 \%$ \\
\hline $\begin{array}{l}\text { De 5 a } 17 \\
\text { años }\end{array}$ & $17.6 \%$ & $22.4 \%$ & $16.3 \%$ & $24.7 \%$ & $23.2 \%$ & $14.4 \%$ \\
\hline
\end{tabular}

Fuente: Selected Population Profiles, American Community Survey.

En comparación con el caso español, resulta notorio que también sea el grupo dominicano el que presente el porcentaje más elevado de menores de 18 años entre los diversos colectivos de origen latino.

Tabla 3. Población por grupo de edad y nacionalidad. España, 2009.

\begin{tabular}{|c|c|c|c|c|c|c|c|c|c|c|}
\hline & 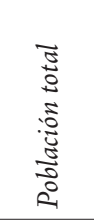 & 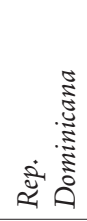 & 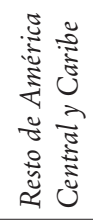 & 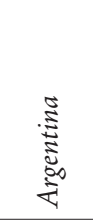 & $\frac{\sqrt[3]{3}}{\stackrel{3}{0}}$ & $\begin{array}{l}\bar{s} \\
\overline{0} \\
0\end{array}$ & $\frac{\tilde{J}}{\tilde{J}}$ & $\frac{0}{\frac{0}{0}}$ & 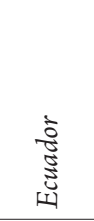 & $\frac{5}{50}$ \\
\hline Total & $100 \%$ & $100 \%$ & $100 \%$ & $100 \%$ & $100 \%$ & $100 \%$ & $100 \%$ & $100 \%$ & $100 \%$ & $100 \%$ \\
\hline $0-4$ & $5.2 \%$ & $4.3 \%$ & $8.0 \%$ & $3.3 \%$ & $4.5 \%$ & $1.9 \%$ & $3.9 \%$ & $2.3 \%$ & $3.2 \%$ & $2.5 \%$ \\
\hline $05-09$ & $4.8 \%$ & $4.5 \%$ & $7.2 \%$ & $5.5 \%$ & $5.0 \%$ & $2.3 \%$ & $5.0 \%$ & $3.2 \%$ & $5.0 \%$ & $3.6 \%$ \\
\hline $10-14$ & $4.6 \%$ & $6.6 \%$ & $4.7 \%$ & $6.0 \%$ & $5.1 \%$ & $2.7 \%$ & $6.0 \%$ & $8.0 \%$ & $9.7 \%$ & $4.9 \%$ \\
\hline $15-19$ & $5.0 \%$ & $9.9 \%$ & $3.1 \%$ & $4.9 \%$ & $4.2 \%$ & $2.7 \%$ & $6.0 \%$ & $9.1 \%$ & $8.9 \%$ & $5.4 \%$ \\
\hline $\begin{array}{l}\text { Total } \\
0-19\end{array}$ & $19.6 \%$ & $25.3 \%$ & $23.1 \%$ & $19.8 \%$ & $18.9 \%$ & $9.6 \%$ & $20.9 \%$ & $22.6 \%$ & $26.8 \%$ & $16.4 \%$ \\
\hline
\end{tabular}

Fuente: Elaboración propia a partir de los datos del PMH, INE.

A diferencia del caso americano, donde una parte considerable de estos menores hijos de padres dominicanos han nacido ya en los EE.UU., en España la mayoría de estos niños y jóvenes han sido reagrupados por sus padres. De hecho, el colectivo dominicano ha presentado en los últimos años un alto potencial de reagrupación familiar, siendo esencialmente las mujeres las que reagrupan, fundamentalmente a los hijos y en segundo lugar a los esposos (Alcalde, 2008; 2010 [b]).

Tal y como veremos, una parte de considerable de estos hijos menores viven en hogares monoparentales encabezados por sus madres. 


\section{La incidencia de la monoparentalidad entre las mu- jeres inmigrantes dominicanas}

Una parte de los menores de edad de origen dominicano viven en hogares monoparentales encabezados por sus madres. Lo que responde, por un lado, al crecimiento de estas formas de hogar en todas las sociedades desarrolladas, pero por otro, a factores relacionados con la situación de vida en los países de origen y con la propia experiencia migratoria.

La literatura especializada señala que una tendencia característica del proceso de modernización de la familia es el incremento del número de hogares monoparentales en las sociedades industrializadas durante las últimas décadas, y en concreto de aquéllos encabezados habitualmente por mujeres ${ }^{3}$. Este fenómeno se produce tanto en la Unión Europea (UE) como en España y en los EE.UU., así como en Latinoamérica y en general en los países emisores de emigración. Ahora bien, lo que constataremos a continuación es que los factores que explican el desarrollo de estas formas de hogar en los países emisores y receptores van más allá de los que son propios de la segunda transición demográfica.

En el caso de los EE.UU., los hogares monoparentales son formas de hogar mucho más frecuentes que en Europa (en 2001 la media de este tipo de hogares era del 4\%, Eurostat), y ciertamente superiores a España (4\% de los hogares, Censo de Población y Viviendas, 2001). Las estimaciones del censo estadounidense realizadas para 2008 valoraban que los hogares monoparentales representaban en este país un $13 \%$ del total de hogares ${ }^{4}$.

Los expertos afirman que España, junto con otros países del sur de Europa - como Portugal, Italia y Grecia-, no ha sufrido transformaciones familiares tan intensas como en el norte de Europa, lo que explicaría, según Treviño (2007), que nuestro país tenga un índice de monoparentalidad más bajo que entre los países europeos vecinos, aunque, eso sí, con una tendencia alcista. Parte de esa tendencia al alza puede explicarse por la formación o llegada a España de familias monoparentales de origen inmigrante, dada la evidencia empírica de la mayor incidencia de estas formas de hogar entre las mujeres de origen inmigrante en España (Alcalde, 2010 [a]). Considerando exclusivamente los hogares con hijos, se ha comprobado que en 2001 los hogares monoparentales representaban el 4,9\% del total (Censo de Población y Vivienda, 2001, INE), una cifra que entre las familias extranjeras alcanzaba el 7,6\%, y entre las españolas el 4,8\%. Las familias encabezadas por madres representaban entonces el 5,6\% del total de ho-

3 Según el Censo de Población y Viviendas de 2001 (INE), del total de hogares monoparentales censados en España, un $99 \%$ estaban integrados por un progenitor con hijos, siendo este en un $81 \%$ de los casos la madre.

4 Fuente: Selected Population Profiles, American Community Survey. 
gares extranjeros con hijos, mientras que entre los hogares españoles únicamente era del 3,8\%. Datos más recientes, como los que aporta la Encuesta Nacional de Inmigrantes (ENI) del año 2007 (INE), muestran que los hogares monoparentales representaban entonces en España el 9,4\% del total de hogares extranjeros encuestados. La ENI indica, a su vez, que estos hogares suelen estar encabezados mayoritariamente por mujeres, con una media de edad de 33,1 años, y en los que conviven una media de 3,4 personas (INE, 2007).

Observando la incidencia de la monoparentalidad según la nacionalidad de las madres, en términos absolutos las nacionalidades en las que se contabilizaron mayor número de este tipo de hogar fueron la marroquí (12,3\% del total de hogares extranjeros integrados por una mujer adulta con uno o más menores a su cargo), seguida de la colombiana (11,6\%), la británica (8\%), la alemana $(7,7 \%)$ y la ecuatoriana $(6,4 \%)$. Por lo que respecta a los términos relativos en relación a cada colectivo, cabe destacar nacionalidades como la guineana, que presentaba una incidencia del 6,6\%; la brasileña $(6,5 \%)$, la dominicana $(6,4 \%)$, la hondureña $(6 \%)$ y la rusa (6\%), entre otras (Censo de Población y Vivienda 2001, INE).

Tabla 4. Tipos de hogar por grupo racial. EE.UU., 2008.

\begin{tabular}{|c|c|c|c|c|c|c|}
\hline & 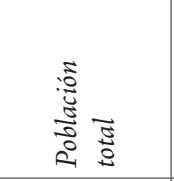 & 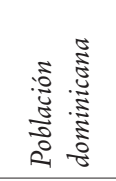 & 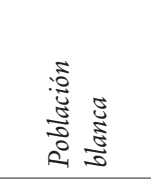 & 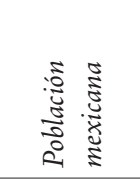 & 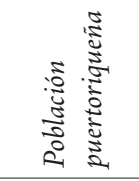 & 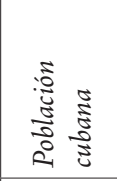 \\
\hline Total hogares & 112.386 .298 & 366.559 & 87.920 .932 & 7.329 .776 & 1.318 .574 & 574.644 \\
\hline Hogares familiares & $66.6 \%$ & $79.4 \%$ & $66.0 \%$ & $80.6 \%$ & $69.6 \%$ & $69.4 \%$ \\
\hline $\begin{array}{l}\text { Hogares familiares } \\
\text { con menores de } 18 \\
\text { años }\end{array}$ & $31.0 \%$ & $50.1 \%$ & $28.9 \%$ & $53.1 \%$ & $40.8 \%$ & $30.1 \%$ \\
\hline Parejas & $49.6 \%$ & $35.8 \%$ & $52.4 \%$ & $53.9 \%$ & $37.6 \%$ & $50.6 \%$ \\
\hline $\begin{array}{l}\text { Parejas con hijos } \\
\text { menores de } 18 \text { años }\end{array}$ & $21.4 \%$ & $22.1 \%$ & $21.4 \%$ & $36.4 \%$ & $19.8 \%$ & $21.6 \%$ \\
\hline $\begin{array}{l}\text { Hogar encabezado } \\
\text { por una mujer, sin } \\
\text { marido presente en la } \\
\text { familia }\end{array}$ & $12.5 \%$ & $35.4 \%$ & $9.5 \%$ & $17.1 \%$ & $25.4 \%$ & $13.0 \%$ \\
\hline $\begin{array}{l}\text { HEMSM con niños } \\
\text { menores de } 18 \text { años }\end{array}$ & $7.4 \%$ & $24.5 \%$ & $5.5 \%$ & $11.8 \%$ & $17.4 \%$ & $6.3 \%$ \\
\hline Hogar no familiar & $33.4 \%$ & $20.6 \%$ & $34.0 \%$ & $19.4 \%$ & $30.4 \%$ & $30.6 \%$ \\
\hline $\begin{array}{l}\text { Hogar encabezado } \\
\text { por hombre }\end{array}$ & $15.5 \%$ & $9.0 \%$ & $15.6 \%$ & $11.8 \%$ & $15.0 \%$ & $15.2 \%$ \\
\hline Vive solo & $12.1 \%$ & $6.7 \%$ & $12.2 \%$ & $7.8 \%$ & $11.7 \%$ & $11.9 \%$ \\
\hline
\end{tabular}

Fuente: Selected Population Profiles, American Community Survey. 
Se ha comprobado igualmente que en los EE.UU. estas formas de hogar están mucho más presentes entre las familias negras e hispanas; en concreto, la incidencia en el colectivo de mujeres dominicanas es especialmente alta: del total de hogares, el 35\% eran monoparentales.

En la Tabla 4 se aprecia, en primer lugar, que el porcentaje de menores de 18 años que viven en este tipo de hogares en los EE.UU, es notablemente mayor entre la población de origen inmigrante o perteneciente a un grupo étnico, y especialmente considerable entre los hogares dominicanos en comparación con otros colectivos (un 50\%). En un 35\% de los hogares dominicanos se trata de familias monoparentales encabezadas por mujeres, lo que representa el valor más alto de los grupos analizados. Y gran parte de estos hogares cuenta con menores de 18 años de edad a su cargo (25\%).

Las causas que pueden explicar esta mayor representatividad de esta forma de hogar entre las mujeres de origen inmigrante residente en los EE.UU. y en España deben analizarse a partir de los elementos propios del país de origen, y por tanto antes del momento de la emigración, pero también a partir de los elementos que encuentran en la sociedad receptora (situación de vida y experiencia migratoria), es decir, después de la emigración.

En la actualidad, resulta bastante común relacionar a las familias monoparentales con pobreza y ruptura del hogar, aunque las causas de la monoparentalidad no siempre están sujetas a estos factores y pueden responder también a una opción de vida elegida. El estudio de estos hogares en el ámbito de la inmigración permite evidenciar hasta qué punto la experiencia migratoria puede constituir una estrategia emancipadora para algunas mujeres que eran, o se convirtieron, en cabezas en solitario de sus hogares.

Con todo, y tal como señalan Oliveira y Ariza (2007), la monoparentalidad entre las mujeres latinoamericanas debe ser examinada considerando si es resultado de un contexto de cambios sociales y demográficos propios de la segunda transición demográfica, o contrariamente como resultado del empobrecimiento. En este sentido, el estudio de la relación entre proyecto migratorio y monoparentalidad aporta interesantes elementos de análisis tanto por lo que respecta a las causas que originan la emigración de estas mujeres y madres, como por las vías de entrada a esta situación familiar.

En el caso concreto de la monoparentalidad entre las mujeres latinoamericanas, estudios diversos realizados por numerosas organizaciones - como son los Informes Nacionales de Derechos Humanos de las Mujeres realizados por ELA (Argentina), Coordinadora de la Mujer (Bolivia), SISMA (Colombia), Corporación Humana (Chile), Taller Comunicación Mujer (Ecuador) o DE- 
MUS (Perú) - constatan estadísticamente que, por ejemplo, en Argentina, estos hogares han experimentado un crecimiento de un 5\% desde el año 1991. En el caso de Ecuador, un 9,5\%. En Chile, para el periodo intercensal 1992-2002, las familias monoparentales aumentaron de un $8,6 \%$ a un 9,7\%. En Perú, aproximadamente un $10 \%$ de las familias son monoparentales, la mayoría de las cuales se hallan encabezadas por mujeres. Los informes señalan igualmente que en Bolivia se está experimentando un aumento de la prefectura de hogares femeninos. Todos estos valores se encuentran notablemente por encima de los que se dan en el caso español.

Si bien en España ha venido siendo estudiado de forma recurrente cuál es el riesgo de pobreza una vez se entra en la monoparentalidad, estos mismos estudios referidos a Latinoamérica, así como los datos del censo norteamericano que aquí hemos mostrado, manifiestan que la pobreza constituye un factor que explica también la formación de estas formas de familia. Un indicador evidente es el hecho de que la monoparentalidad afecta en mayor medida a aquellos grupos sociales y étnicos tradicional y socialmente vulnerables, como es el caso de las mujeres inmigrantes y sus hijos en España y los EE.UU., o el de la población hispana y afroamericana en éste último país. Esto evidencia que, si bien una situación de monoparentalidad puede representar una mayor fragilidad social para las madres y sus hijos, una situación de pobreza previa puede facilitar la entrada a la monoparentalidad femenina, retroalimentado de esta manera el círculo de la pobreza.

El siguiente gráfico permite observa con cierta nitidez que en los EE.UU. los hogares monoparentales han prevalecido durante los últimos 30 años entre las familias afroamericanas, $y$ en segundo lugar entre las familias hispanas.

Autores como Peter David Brandon (2000) han sostenido, a través de la explotación de los datos del Current Population Survey, que los niños hispanos nacidos en el extranjero viven en mayor medida en hogares con ambos padres de lo que lo hacen los niños blancos nacidos en los EE.UU. Es decir, según su tesis, a medida que la población extranjera se asienta en la sociedad de recepción, aumenta la incidencia de la monoparentalidad entre estos colectivos, acomodándose las pautas familiares a las americanas. Ahora bien, los datos de serie aportados por la Oficina del Censo de los Estados Unidos provocan, al contrastarlos con los datos de Brandon, algunas controversias. En el gráfico que viene a continuación aparece representada la diferencia entre el porcentaje de estos hogares entre las familias hispanas y las blancas (\% familias monoparentales hispanas - \% familias monoparentales blancas), donde puede apreciarse que en los últimos 30 años, en los EE.UU. siempre ha habido más familias monoparentales entre la población hispana. 
Gráfico 1. Evolución de los hogares monoparentales con menores de 18 años de edad por grupo racial. EE.UU., 1980-2009.



Fuente: elaboración propia a partir de los datos del Selected Population Profiles, American Community Survey.

Gráfico 2. Comparación entre las familias monoparentales hispanas y blancas. EE.UU., 1980-2009.

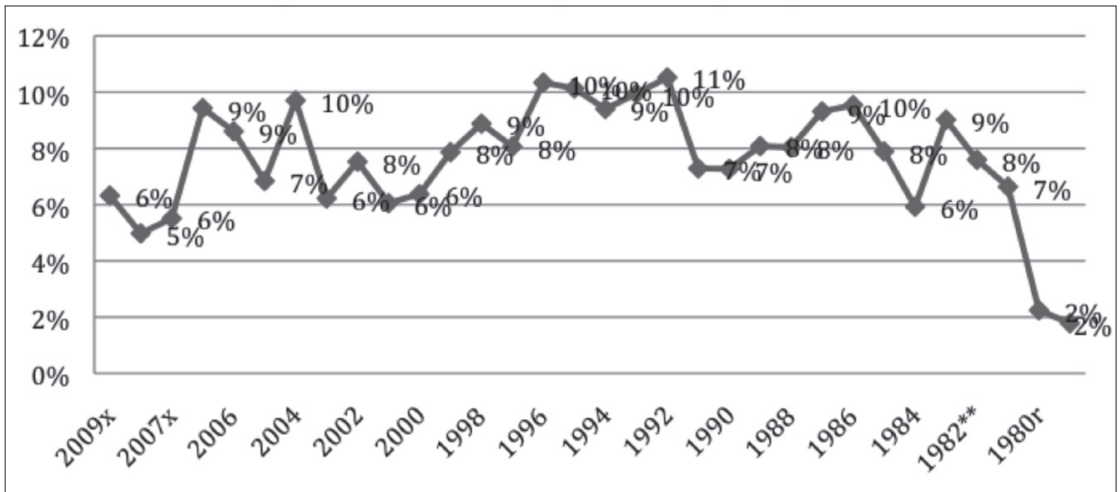

Fuente: elaboración propia a partir de los datos del Selected Population Profiles, American Community Survey.

Estos datos vienen a demostrar:

a) El crecimiento de los hogares monoparentales en los EE.UU. se ha producido de forma muy notable en ambos grupos (blancos, hispanos) durante los últimos 30 años. 
b) La incidencia de la monoparentalidad siempre ha sido mayor entre el colectivo hispano que entre el de la población blanca.

c) Este crecimiento ha sido muy superior entre los hogares hispanos.

d) La prevalencia de la monoparentalidad entre el colectivo hispano es hoy mayor que hace 20 años.

Lo que probablemente no consideró David Brandon es que la situación de las familias hispanas es enormemente diversa, y que entre aquellas en las que se han producido experiencias de emigración y procesos de reagrupación familiar pueden darse un mayor riesgo de disrupción marital. Existen diversos estudios que indagan precisamente sobre el estrés al que se ve sometida la familia con la experiencia de emigración, y cómo ello afecta a las relaciones intrafamiliares (Suárez-Orozco, 2003; Miranda, 2002; Smajkic y Wane, 1995; en España‡ Parella y Lurbe (et alii), 2006; Lurbe y Alcalde (et alii), 2007; Pedone, 2003, 2004).

Así pues, sería pertinente poder realizar un tipo de análisis más intensivo de este colectivo, pero diferenciando, efectivamente, entre las familias monoparentales con experiencias migratorias y de reagrupación familiar, y las familias que se han creado ya en las sociedades de asentamiento.

\section{Monoparentalidad e inmigración}

En el caso concreto del colectivo dominicano, debemos saber que la alta presencia de este tipo de hogares se produce tanto en el país de origen como en los países receptores de la inmigración dominicana. Ya en el año 1991, Tejada (1996) destacaba cómo alrededor del $45 \%$ de las mujeres dominicanas de entre 15 y 49 años de edad vivían sin hombres, y que este colectivo constituía el 69,2\% de las que encabezaban sus respectivos hogares. Por tanto, podríamos añadir también un factor cultural en relación a la aceptación de estas formas familiares - cuestión sobre la que reflexionan Gurak y Gilbertson (1990, 1992)_, posiblemente de carácter emancipador. En relación a los factores que se dan en el país de origen, un hecho que probablemente explique el elevado número de hogares monoparentales puede ser la elevada presencia de uniones consensuadas, que en 2002 representaban el 33\% de los estados civiles (Censo Dominicano).

Según el trabajo de Gurak y Gilbertson (1990), en el que se contrasta la situación de las mujeres dominicanas con la de mujeres colombianas migrantes, las uniones consensuadas representan una mayor probabilidad de disrupción marital, y por tanto de que las mujeres pasen a encabezar sus respectivos hogares. Entre los elementos previos a la emigración que los autores consideraron que 
incidían en la disrupción marital hallaron el nivel de estudios y la formación, ya que la presencia de este tipo de hogares era mayor entre aquellas mujeres migrantes con un bajo nivel de estudios. Por tanto, se entiende que existe una relación entre nivel de estudios y formación $-\mathrm{y}$, consecuentemente, situación económica-, uniones consensuadas y hogares monoparentales. Cabría indagar hasta qué punto se producen, entre el colectivo dominicano, estas correlaciones: a menor nivel de estudios y formación - es decir, bajos ingresos pecuniarios-, aumenta el riesgo de uniones consensuadas, y éstas, a su vez, incrementan el riesgo de disrupción de la relación de pareja, dando lugar a hogares encabezados por mujeres, lo que las sitúan en una posición económica altamente vulnerable que puede determinar la decisión de emigrar.

Con todo, las formas de acceso a estos tipos de hogar entre las mujeres migrantes son muy diversas. En general, pueden agruparse en la taxonomía realizada por Iglesias (1988) (citado por Vicente y Royo, 2006: 28). Este autor diferencia entre: a) las vinculadas a la natalidad: madres solteras con uno o más hijos nacidos fuera del matrimonio o en el seno de una pareja de hecho, en estos momentos rota; b) las vinculadas a la relación matrimonial, cuando un progenitor queda a cargo de los hijos (abandono familiar, anulación del matrimonio, separación de hecho o separación legal del matrimonio, divorcio, viudedad con hijos a cargo, etc.); c) las vinculadas al ordenamiento jurídico: adopción por personas viudas, solteras, separadas o divorciadas; $y d$ ) las vinculadas a situaciones sociales, en las cuales no se produce una ruptura conyugal pero tampoco se da convivencia entre la pareja, lo que genera situaciones de monoparentalidad en términos prácticos, aunque este estatus no esté reconocido legalmente: hospitalización, migración, encarcelación, realización de alguna profesión como marino o militar, etc.

En este artículo nos centraremos fundamentalmente en aquellas vías de entrada relacionadas con la disrupción de las relaciones de parejas, ya sean por matrimonio o por unión consensuada.

Considerando de nuevo para el caso español los datos del Censo de Población y Viviendas de 2001 (INE), puede comprobarse que las vías de acceso a la monoparentalidad predominantes entre las mujeres extranjeras residentes en nuestro país están relacionadas con la natalidad, seguidas de las vinculadas al matrimonio, con o sin disolución; mientras, entre las mujeres españolas suelen ser en mayor medida causas ligadas al matrimonio. Así, entre los hogares integrados por una mujer adulta con uno o más menores a su cargo, en el 35\% de los casos las mujeres extranjeras tenían un estado civil de soltería, mientras que entre las mujeres españolas el $30 \%$ estaban casadas y un 28\% separadas. Resulta de igual modo interesante observar que el porcentaje de mujeres que encabezaban estos 
hogares y que tenían un estado civil de casadas era relativamente elevado entre las mujeres extranjeras $(27,8 \%)$. De ello se deduce que son situaciones en que, o bien no se había producido la ruptura conyugal, aunque la pareja no conviviera - lo que genera una situación de monoparentalidad de hecho-, o bien se había producido un abandono familiar o se trataba de situaciones sociales relacionadas con la migración.

En el caso de las mujeres dominicanas, el porcentaje de las que poseían el estado civil de soltera es notablemente superior tanto a los valores totales como en relación a la mayoría del resto de nacionalidades latinoamericanas presentes en España. Al mismo tiempo, el porcentaje representativo de mujeres casadas aporta uno de los valores más bajos.

Gráfico 3. Hogares extranjeros formados por una mujer adulta con uno o más menores a su cargo, por nacionalidad y estado civil. España, 2001.

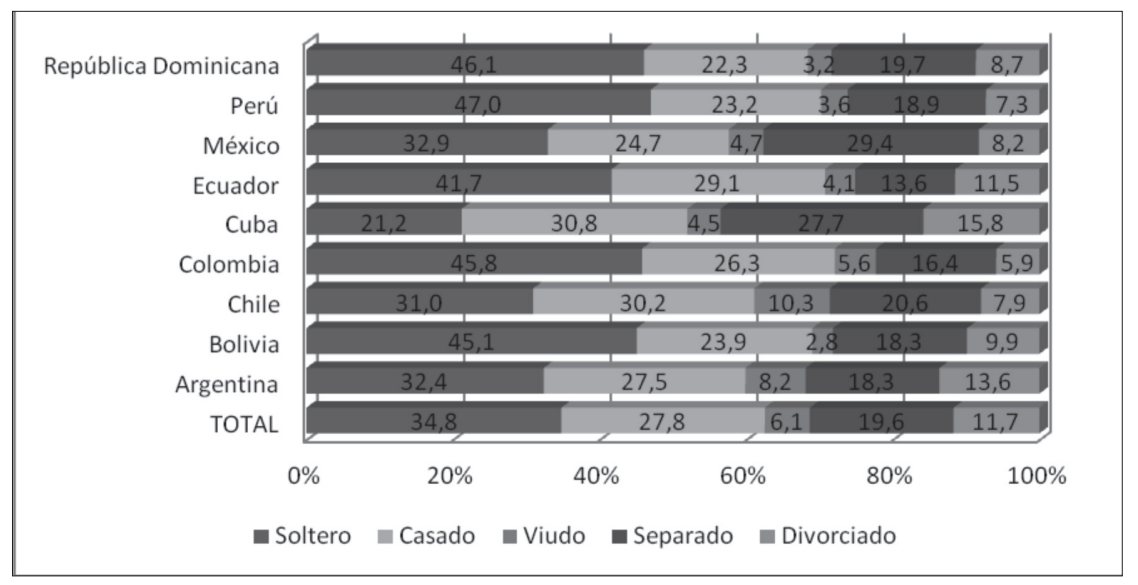

Fuente: elaboración propia a partir de los datos del Censo de Población y Viviendas 2001, INE.

El trabajo cualitativo llevado a cabo con dieciocho mujeres de diferentes nacionalidades latinoamericanas en España sugiere que las vías de acceso a la monoparentalidad presentan una rica complejidad, de la que difícilmente puede dar cuenta la categoría estadística «estado civil». Lo cierto es que un número considerable de ellas, si bien constarían como solteras, son, en realidad, mujeres separadas de sus parejas de hecho. Este fue el caso de las cuatro mujeres dominicanas entrevistadas en Barcelona y el de cinco de las seis mujeres dominicanas entrevistadas en Nueva York. 
En el caso de las mujeres inmigrantes latinoamericanas, conviene considerar que las pautas de unión conyugal, tal y como señalan Oliveira y Ariza (2007), son un factor sociocultural y demográfico de gran relevancia en América Latina, y poseen también una influencia decisiva. La mayor presencia de uniones de hecho se asocia con una alta inestabilidad conyugal, y por tanto con una creciente probabilidad de formación de hogares monoparentales o extensos encabezados por mujeres. El análisis de Oliveira y Ariza incide en un aspecto relevante: el aumento de las uniones de hecho y el leve retraso en cuanto a la edad media de las mujeres a la hora de establecer estos enlaces, tienen una explicación diferente según se trate de extractos sociales medios y altos, o bien de extractos populares, lo que cuadra con la tesis de Gurak y Gilbertson (1990). En cierto modo, en los sectores sociales medios y altos estos fenómenos pueden responder a factores análogos a los casos europeo y estadounidense; es decir, a una mayor autonomía de las mujeres. En los sectores empobrecidos - aunque no excluimos la existencia de situaciones reales de mayor autonomía femenina-, sería más apropiado asociar algunas de las transformaciones en curso al constante deterioro de los niveles de vida. En este sentido, el proyecto de emigrar vinculado a la monoparentalidad conlleva representaciones igualmente diferenciadas en función de si la monoparentalidad es resultado de una mayor autonomía o como consecuencia del empobrecimiento.

Los resultados de la investigación llevada a cabo en España vislumbran cinco situaciones que relacionan la migración de mujeres latinoamericanas con la formación de hogares monoparentales en la sociedad de destino derivada de la ruptura de la relación de pareja.

1. La monoparentalidad se produce en el país de origen y responde a unos factores causales vinculados a la pobreza. Consecuentemente, la emigración se configura como una estrategia de supervivencia del núcleo familiar.

2. La jefatura de hogar ya se producía en solitario en el país de origen y la emigración es el resultado del afianzamiento de un proyecto vital emancipador como estrategia de mejora del núcleo familiar.

3. La emigración se convierte en una estrategia clave para fundar un hogar monoparental en el país de destino, y consecuentemente se configura como forma una forma de emancipación ${ }^{5}$.

\footnotetext{
5 Debe considerarse que en esta investigación se han estudiado los casos de mujeres que actualmente encabezan hogares monoparentales en el país de destino de la emigración, y por tanto sus hijos o parte de ellos conviven con ellas en España. Por tanto, no se abordaron aquellas situaciones en las que las madres son cabeza de un hogar monoparental, pero mantienen a sus hijos en el país de origen, basando su proyecto migratorio en el envío de remesas.
} 
4. La emigración debilita el lazo matrimonial cuando la pareja está separada, dando lugar a la disrupción de la relación y a la formación del hogar monoparental en el país de destino.

5. La emigración comporta un elevado grado de estrés en la relación de pareja, muchas veces derivado de la renegociación de roles, lo que genera la disrupción de la relación y la consecuente formación del hogar monoparental en el país de destino.

En cambio, en el caso de los EE.UU. aparece un perfil que nos remite a mujeres que fueron reagrupadas durante la infancia por sus padres y que han sido socializadas en Nueva York, habiéndose configurado por tanto la familia monoparental en el país de destino. Es decir, que son las segundas generaciones de mujeres migrantes dominicanas las que encabezan hogares monoparentales. Cinco de ellas tuvieron como vía de entrada a la monoparentalidad la tenencia de hijos en el seno de parejas de hecho que se encontraban en ese momento rotas. En este caso podría pensarse en una asimilación de la pauta propia de los segmentos más empobrecidos de la primera generación, dadas las condiciones de vida en que se hallaban en el momento de formar estos hogares.

\section{Las condiciones de vida de los hogares monoparen- tales encabezados por mujeres migrantes en Barcelo- na y en Nueva York}

En un análisis de la pobreza desde la perspectiva de su entrada en ella, puede afirmarse que los hogares monoparentales presentan en su conjunto unas entradas económicas inferiores a otros tipos de hogar - 6.700 euros es la renta media anual por persona entre los hogares monoparentales españoles, frente a la media total de 8.916 euros (Encuesta de Condiciones de Vida 2007, INE) - . En el caso estadounidense, la media de ingresos anuales por hogar se situaba en 2009 en los $49.777 \$$, mientras que entre las familias monoparentales descendía hasta los 29.085 \$ (Oficina del Censo) ${ }^{6}$.

Por otra parte, el trabajo de campo cualitativo en España muestra que los ingresos anuales de las familias monoparentales extranjeras entrevistadas son aún inferiores a estos valores, situándose en los 4.102,84 euros (Alcalde, 2010 [a]).

Para el caso de los EE.UU, si consideramos los porcentajes entre los hogares situados por debajo del umbral de la pobreza en relación a los ingresos, tipo de

6 Enlace a las tablas originales: http://www.census.gov/hhes/www/cpstables/032010/rdcall/toc.htm). 
hogar y grupo étnico, las diferencias entre grupos étnicos son notablemente apreciables, al igual que entre los hogares monoparentales encabezados por mujeres?

Tabla 5. Porcentaje de hogares por debajo del umbral de la pobreza, por ingresos económicos (antes de los impuestos) y grupo étnico. EE.UU., 2009

\begin{tabular}{|c|c|c|c|c|c|}
\hline & $\begin{array}{l}\text { Población } \\
\text { total } \\
\text { (miles) }\end{array}$ & $\begin{array}{c}\text { Excluyendo las } \\
\text { ganancias de } \\
\text { capital (medida } \\
\text { actual) }\end{array}$ & $\begin{array}{l}\text { Sin las } \\
\text { transferencias } \\
\text { del gobierno }\end{array}$ & $\begin{array}{l}\text { Más las } \\
\text { ganancias } \\
\text { de capital }\end{array}$ & $\begin{array}{l}\text { Más el seguro } \\
\text { de salud } \\
\text { suplementario } \\
\text { y el sueldo }\end{array}$ \\
\hline $\begin{array}{l}\text { TODAS LAS } \\
\text { FAMILIAS }\end{array}$ & 78.867 & $11.1 \%$ & $21.0 \%$ & $21.0 \%$ & $20.3 \%$ \\
\hline $\begin{array}{l}\text { Mujeres cabeza de hogar } \\
\text { sin presencia de esposo } \\
\text { con bijos a cargo menores } \\
\text { de } 18 \text { años }\end{array}$ & 9.872 & $38.5 \%$ & $45.8 \%$ & $45.8 \%$ & $44.1 \%$ \\
\hline \multicolumn{6}{|c|}{ HISPANOS } \\
\hline Todas las familias & 10.422 & $22.7 \%$ & $29.7 \%$ & $29.7 \%$ & $28.6 \%$ \\
\hline $\begin{array}{l}\text { Mujer cabeza de hogar } \\
\text { sin presencia de esposo } \\
\text { con bijos menores de } 18 \\
\text { años }\end{array}$ & 2.055 & $46.0 \%$ & $51.3 \%$ & $51.3 \%$ & $49.5 \%$ \\
\hline \multicolumn{6}{|c|}{ NEGROS } \\
\hline $\begin{array}{l}\text { Mujer cabeza de hogar } \\
\text { sin presencia de esposo } \\
\text { con hijos menores de } 18 \\
\text { años }\end{array}$ & 2.996 & $44.2 \%$ & $52.0 \%$ & $52.0 \%$ & $50.0 \%$ \\
\hline \multicolumn{6}{|c|}{ BLANCOS } \\
\hline $\begin{array}{l}\text { Mujer cabeza de hogar } \\
\text { sin presencia de esposo } \\
\text { con hijos menores de } 18 \\
\text { años }\end{array}$ & 6.300 & $36.1 \%$ & $43.1 \%$ & $43.1 \%$ & $41.6 \%$ \\
\hline \multicolumn{6}{|c|}{ ASIÁTICOS } \\
\hline $\begin{array}{l}\text { Mujer cabeza de hogar } \\
\text { sin presencia de esposo } \\
\text { con hijos menores de } 18 \\
\text { años }\end{array}$ & 248 & $22.5 \%$ & $28.8 \%$ & $28.8 \%$ & $27.3 \%$ \\
\hline
\end{tabular}

Fuente: Selected Population Profiles, American Community Survey.

7 Sobre el riesgo de pobreza en este tipo de hogares para la población afroamericana, ver Page, Steven (2005). 8 En el caso estadounidense, las bases de datos no permiten distinguir las categorías de nacionalidad ni la de inmigrante, por lo que la categoría «grupo étnico» incluye las propias adscripciones de cada una de las personas a un grupo, ya sean inmigrantes, extranjeros o ciudadanos americanos. Los factores que explican una mayor incidencia y persistencia de la pobreza entre los grupos étnicos hispano y negro en este país van más allá de los que en esta investigación se han explorado. 
En la investigación a la que aquí nos remitimos se puso el énfasis en dilucidar de qué forma la emigración se configuraba como una estrategia de superación de la pobreza entre aquellos perfiles de mujeres que encabezaban hogares monoparentales en el país de origen, y que respondían a niveles socioculturales medio y medio-bajos. En estos casos, la emigración constituía una estrategia de supervivencia del núcleo y de superación de la pobreza en el país de origen, principalmente cuando el modelo migratorio estaba basado en el envío de remesas. Ahora bien, se ha verificado que el éxito de esta estrategia en términos de superación de la pobreza es cuestionable cuando se produce la reagrupación familiar. A la luz de nuestros resultados, de los dieciocho hogares monoparentales encabezados por mujeres extranjeras en España, sólo tres superaban el umbral de la pobreza moderada, que en 2007 se situaba en los 6.405,6 euros ${ }^{9}$. Además, dos de ellos estaban encabezados por mujeres con orígenes socioculturales altos. De todo ello se concluye que la incidencia de la pobreza entre las mujeres de la muestra española es considerablemente alta (78\%). De entre estos quince casos de familias que se encontraban por debajo del umbral de la pobreza, ocho presentaban una situación de pobreza elevada, y de estos, en dos la vía de entrada había sido causada por la viudedad sobrevenida en España, mientras que en el resto respondía en su mayoría a causas vinculadas con la natalidad y la tenencia de hijos dentro del seno de parejas de hecho.

De igual forma, podemos afirmar que entre las familias monoparentales extranjeras entrevistadas en Barcelona prevalecían las situaciones de pobreza persistente, y diez de ellas presentaban una situación de riesgo de exclusión social si consideramos la combinación de los siguientes elementos: bajo nivel de ingresos derivado de las bajas rentas del trabajo y de la ausencia de la manutención de los padres de sus hijos e hijas; precarias condiciones de trabajo (contratos temporales en el sector de la limpieza, hostelería, o similares) e imposibilidad de movilidad laboral; dificultades de acceso a la formación; precarias condiciones de vivienda (viviendas compartidas, subalquiler de habitaciones, etc.); así como la debilidad de las redes familiares y de amistad.

Muchos de estos factores fueron también reconocidos entre los casos de mujeres dominicanas en Nueva York, y especialmente los laborales (sueldo, tipo de contrato y de jornadas laborales). Sin embargo, hay dos elementos entre las mujeres dominicanas neoyorquinas que, a diferencia de los casos de otras mujeres latinas analizados en Barcelona, amortiguan los efectos de la pobreza severa y la exclusión: la existencia de redes de ayuda familiares y públicas, especialmente las orientadas a la vivienda. Este tipo de prestaciones sociales también cubren, en la

9 Ninguna de las tres familias españolas de control vivían en situación de pobreza. 
ciudad de Nueva York, el seguro médico y la escolarización de los hijos, derechos ambos reconocidos en España a partir de la residencia, lo que permite el acceso a las personas extranjeras a la red de servicios públicos universales (educación, sanidad, servicios sociales). Resulta necesario confeccionar un estudio que estableciera una comparación de los niveles de pobreza en ambos contextos, y también dentro de este colectivo considerando la perspectiva del ingreso - y analizando el tipo de prestaciones otorgadas por ambos Estados (cantidad y cualidad) - y del gasto que las familias dedican a estos servicios, esencialmente educación y sanidad.

En cuanto a las redes de ayuda, debemos considerar que la inmigración dominicana comenzó a instalarse de forma masiva en Nueva York hacia mediados de la década de 1980, por lo que ya se ha configurado y consolidado una red migratoria familiar sólida en este territorio. Por otro lado, y en relación a la cultura familiarista entre las familias dominicanas, hay algunos autores que confirman que en la República Dominicana se conservan con fuerza las relaciones primarias, se concede una alta valoración a los lazos de parentesco y poseen importancia las relaciones vecinales-familiares (Vargas, 1998; Tejada, 1996). De igual modo, prevalece el modelo de familia extensa y compuesta, si bien se aprecian diferencias dependiendo del entorno (urbano-rural). Lo que resulta significativo es que también entre las familias dominicanas que residen en Nueva York parece reproducirse esta estructura familiar (McGoldrick, Giordano y Garcia-Preto, 2005), por lo que resulta muy probable que así ocurra también en el caso español, dado que en tres de las cuatro mujeres de nacionalidad dominicana que se entrevistaron en Barcelona se reproducía también este modelo.

\section{Conclusiones}

Si bien la entrada a la monoparentalidad puede ser consecuencia de una decisión personal y constituir una forma de emancipación para las mujeres migrantes, es importante conocer cuáles son los condicionantes que explican la decisión de emigrar, y si efectivamente el proyecto migratorio es una estrategia para superar la pobreza en la monoparentalidad, o bien constituye una estrategia de emancipación.

Un aspecto relevante son las propias condiciones en que se producen estas formas de hogar en los países de origen de estas mujeres: se ha constatado que existe una relación previa entre pobreza, uniones de hecho y monoparentalidad.

Es importante observar que las uniones de hecho son, en alto grado, previas a la monoparentalidad en los países latinoamericanos, lo que deja a muchas de 
estas mujeres y sus hijos en una situación de enorme vulnerabilidad. Los estudios ratifican que la extensión de estas formas de familia en Latinoamérica no ha venido acompañada del reconocimiento de derechos en cuanto a aspectos de autonomía económica y de la propia condición femenina. Los ordenamientos normativos del Perú, Ecuador y Colombia reconocen las uniones de hecho. No obstante, cabe destacar los sesgos legales y culturales que favorecen la unión matrimonial y atribuyen, de hecho, la propiedad de los bienes familiares al hombre, mientras las mujeres y sus hijos permanecen a menudo en situación de fragilidad; se convierten, así, en las mujeres más pobres. Por ende, la monoparentalidad como consecuencia de la tenencia de hijos dentro de parejas de hecho presenta un mayor riesgo de sufrir situaciones de vulnerabilidad social una vez se diluye la relación. Con todo, los estudios sobre la materia señalan que en los países latinoamericanos éste es un factor de riesgo de exclusión que probablemente sea mayor en aquellos países con políticas sociales y de protección a las familias más débiles (Sunkel, 2006). Cabría estudiar el caso específico de la República Dominicana.

Los relatos de las mujeres entrevistadas ponen de manifiesto que el significado y la vivencia de su jefatura de hogar oscilan entre lo irremediable y lo deseado. Por otra parte, la imbricación de la pobreza en estas formas de hogar es compleja y requiere de un análisis mucho más pormenorizado del aquí realizado. Por ello proponemos como una posible línea de trabajo invertir el análisis entre monoparentalidad y pobreza que, por lo general, realizamos en los países más desarrollados, para plantear estudios que analicen de qué forma la pobreza aumenta el riesgo de creación de un hogar monoparental, y cómo esto retroalimenta, a su vez, el círculo de la pobreza. Esta situación, por otra parte, no parece darse cuando la emigración se plantea como estrategia de mantenimiento del núcleo monoparental, a la hora de reagrupar a los hijos. Las condiciones de vida de estas mujeres y de sus hijos son muy frágiles como consecuencia de las débiles redes familiares y de amistad, de las condiciones laborales de los puestos de trabajo que desempeñan, de las dificultades de acceso a la vivienda y de la ausencia de apoyo económico por parte de los padres de sus hijos.

En el caso de las mujeres migrantes, y contrastando los perfiles trabajados en Barcelona y Nueva York, aparecen varios elementos que justificarían este tipo de estudios.

El primero, la importancia de estudiar de qué forma se produce la entrada a la monoparentalidad en los países emisores de emigración, y si ésta está relacionada con la pobreza o bien con los cambios sociales y demográficos propios de la segunda transición demográfica. 
En segundo lugar, sería necesario indagar hasta qué punto la experiencia migratoria representa en si misma un mayor riesgo de ruptura conyugal con el consecuente aumento de las familias monoparentales en los países de destino de la inmigración, aumentando así el riesgo de pobreza en la sociedad de asentamiento. En este caso, podría resultar novedoso el estudio de dos contextos como el neoyorquino y el español.

Por último, el caso de las mujeres dominicanas en Nueva York ha permitido vislumbrar lo relevante que resultaría el análisis de estas formas de hogar entre las hijas de padres migrantes que han sido socializadas en las sociedades de recepción de la inmigración, estudiando la relación entre pobreza y monoparentalidad y la reproducción de estas pautas conyugales intergeneracionales.

\section{Bibliografía}

Alcalde, R. (2010) (a). La monoparentalitat en la immigració. Un factor de risc de pobresa entre les mares $i$ els infants d'origen estranger. Informe de Investigación. Institut Català de les Dones.

Alcalde, R. (2010) (b). «Las reagrupaciones familiares y sus efectos en el bienestar de los menores migrantes: manifestaciones y detección en el ámbito escolar». Migraciones, 8: 127-156.

Alcalde, R.; Lurbe, K.; Benítez, I.; Bejarano, L.; Bermann, S., y Solé, C. (2008). La integració comença aqui: els efectes de les reagrupacions familiars en les politiques i serveis municipals. Informe de investigación. Entidad financiadora: AGAUR. Generalitat de Catalunya.

Ariza (2004). «Obreras, sirvientas y prostitutas. Globalización, familia y mercados de trabajo en República Dominicana». Estudios Sociológicos, 22 (1): $123-149$.

Arriagada, I. (1991). «Mujeres rurales de América Latina y el Caribeः resultados de programas y proyectos»., en Una nueva lectura. Género en el desarrollo. Lima, Perú: Entre Mujeres.

Ayala, L.; Martínez, R.; Sastre, M. (2006). Familia, infancia y privación social. Estudio de las situaciones de pobreza social en la infancia. Cáritas y Fundación FOESSA. (Colección Estudios, n+ ${ }^{\circ}$ 14).

Brandon, P+ (2000). «The Living Arrangements of Children in Immigrant Families in the United States». International Migration Review, 36 (2):416-436.

Brydon, L.; Chant, S. (1993). Women in the Third Worl: Gender Issues in Rural and urban Areas. New Brunswick: Rugers University Press. 
Fernandez-Kelly, P. (1983). For We Are Sold, I and My People. Women and Industry in Mexico's Frontier. Albany: State University of New York Press.

Flaquer, L*; Almeda Samaranch, E*, y Navarro Varas, L. (2006). Monoparentalitat $i$ infància. Barcelona: Fundació La Caixa.

Gallardo Rivas, G. (1995). Buscando la vida: dominicanas en el servicio doméstico en Madrid. Santo Domingo: Co-edición IEPALA/CIPAF.

Garfinkel, I.; McLanaham, S. (1987). Single Mother and their children. A New American Dilemma. Washington DC: The Urban Institute.

George, E. (1992). «Gender, Class, And Migration in the Dominican Republic Women's Experiences in a Transantional Community», en Glick, N.; Basch, L., y Blanc, C. (Szanton eds.). «Towards a Transnational Perspective on Migraton Race, Class, Ethnicity, and nationalism Reconsidered», en Annals of the New York Academy of Sciences, pp. 81-100.

Gil, G.; Ramírez, C.; Fernández, A. (2000). «¿En España es diferente? Mujeres inmigrantes dominicanas y marroquíes». Papers, Revista de Sociologia, $60 \div 257-273$.

Gilbertson, G.; Gurak, D. T. (1992). «Household Transitions in the Migrations of Dominicans and Colombians to New York». International Migration Review, 26 (1):22-45.

Gonzalez, N. (1970). «Peasants' Progress: Dominicans in New York». Caribbean Studies, $10(3): 36-43$.

- (1974). «Multiple Migratory Experience of Dominicans in New York». Antrhopology Quarterly, 49 (1):36-43.

Grasmuck, S.; Pessar, P. R. (1991). Between Two Islands* Dominican International Migration. Berkeley: University of California Press.

Gurak, D. T.; Gilbertson, G. A. (1990). «Female headship and the migration process: an event history analysis of marital disruption among Dominican and Colombian female immigrants». Population and Development Program Working Paper Series, 2.

Gurak, D.T. (1993). «Social context, Household Composition and Employment Among Migrant and Nonmigrant Dominican Women». International Migration Review, 30 (2): 399-422.

Hendricks, G. T. (1974). The Dominican Diaspora: From the Dominican Republic to New York City: Villagers in Transition. New York: Teachers College Press.

Hernández, R. (2002). The mobility of workers under advanced capitalism. Dominican Migration to the United States. New York: Columbia University Press. 
Hernandez, R.; Rivera-Batiz, F. L. (2003). Dominicans in the United States: a socioeconomic profile, 2000. New York: Dominican Research Monographs. The CUNY Dominican Studies Institute.

Hernanz, R. (1997). «Mujeres dominicanas en el servicio doméstico de Pozuelo/Aravaca». Cuadernos de Relaciones Laborales, 10: 75-101.

Iglesias, D. (1998). La familia y el cambio político en España. Madrid: Tecnos.

Lurbe, K.; Alcalde, R.; Benítez, I.; Bejarano, L.; Bermann, S.; Márquez, J.; SolÉ, C. (2007). La influència del procés de reagrupament familiar sobre les relacions intrafamiliars i el seu benestar biopsicosocial. Informe de investigación. Entidad financiadora: Institut Català de la Dona, Generalitat de Catalunya.

McGoldrick, J. G.; Garcia-Preto, N. (2005). Ethnicity and family therapy. New York: The Guilford Press.

McLanahan, S.S.; Sandefur, G. (1994). Growing Up in a Single-Parent Family: What Hurts, What Helps. Cambridge, MA: Harvard University Press.

Miranda, A.O;; Estrada, D.; Firpo-Jiménenz, M. (2002). «Differences in Family Cohesion, Adaptability, and Environment Among Latino Families in Dissimilar Stages of Acculturation». The Family Journal: counselling and therapy for couples and family, 8 (4):341-350.

Mitchell, C. (1992). «US Foreign Policy and Dominican Migration to the United States», en Mitchell, C. (ed.). Western Hemisphere Migration and United States Foreign Policy. Pennsylvania: Penn State Press.

Oliviera, O; Ariza, M. (2007) «Familias, pobreza y desigualdad social en Latinoamérica: una mirada comparativa». Estudios Demográficos y Urbanos, 22 (1): 9-42. Disponible en: <http //revistas.colmex.mx/revistas/11/ art_11_1156_8779.pdf $>$ [Consulta: 27 de noviembre de 2009].

Page, M. E.; Stevens, A. H. (2005). «Understanding Racial Differences in the Economic Costs of Growing up in a Single-Parent Family». Demography, 42 (1):75-90.

Parella, S.; Lurbe, K.; Samper, S. (2006). Mujeres inmigrantes con hijos a cargo. Detección de necesidades en el ámbito de las politicas familiares y de salud. Madrid: Informe IMU.

Penalo, C. (1987). Parental Attitudes of First and Second Generation Dominican Mothers. Master's Thesis. New York: City College.

Pimentel, A. (2001) «Los dominicanos en España. Los dominicanos en Barcelona». Scripta Nova, 94 (65). Disponible en: <http://www.ub.es/geocrit/ sn-94-65.htm $>$ [Consulta: 26 de julio de 2010]. 
Romero Valiente, J. M. (2003) • «La migración dominicana hacia España. Factores, evolución y desarrollo». Revue Europeénne des Migrations Internationals, $9(1): 147-171$.

SAfa, H. (1998). The Myth of the Breadwinner. Women and Industrialization in the Caribbean. Colorado: Westview.

Schapiro, N.A. (2002). "Issues of separation and reunification in immigrant Latina youth». Nurs Clin North Am, 3 (37):381-392.

SAssen, S. (1981)+ «Exporting Capital and Importing Labor: The Rol of Caribbean Migration to New York City». Ocassional Paper, 28. Center for Latin American and Caribean Studies, New York University.

Sassen, S. (1989). The mobility of Labor and Capital: A study in international investment and labor flow. Nueva York: Cambridge University Press.

Smajkic, A.; Weane, S. (1995). «Acculturation Stress of Hispanics: Loss and Challenge». Journal of Counseling and Development, 75: 390-396.

Sorensen, N. N. (1996). «Nueva York es tan sólo otra capital dominicana. Madrid es otro mundo. Prácticas espaciales y culturales de desplazamiento entre migrantes dominicanos en Nueva York y Madrid». Género y Sociedad, 4: $160-219$.

Spalding, H.A. (1989). «Dominican Migration to New York Cityः Permanent Residents or Temporay Visitor». Migration, 5: 47-68.

Sunkel, G. (2006). El papel de la familia en la protección social en América Latina. Santiago de Chile: CEPAL, ONU.

Tejada Holguín, R. (1996). «Las familias dominicanas: un rompecabezas difícil de armar». Estudios Sociales, 105:7-34.

Vicente, T. L.; Royo, R. (2006). Mujeres al frente de familias monoparentales. Deusto: Universidad de Deusto.

Vicioso, C. (1976). «Dominican Migration to the United States»+ Migration Today, 20: 59-72.

Weyland, K. (1998). «Dominican women "Con un pie aquí y el otro alla’”». En International Migration, Class, Gender and Cultural Change Dissertation. Graduate Faculty of Political and Social Science of New School for Social Research in partial fulfillment of the requirements for the Degree of Doctor of Sociology. New York. 